\title{
Importance of Smoking Cessation in a Lung Cancer Screening Program
}

\author{
Vidit Munshi · Pamela McMahon
}

Published online: 18 September 2013

(c) Springer Science + Business Media New York 2013

\begin{abstract}
Early detection of lung cancer and smoking cessation interventions can decrease lung cancer mortality, but information on the effectiveness and interaction between smoking cessation and lung cancer screening is sparse and inconsistent. This review aims to synthesize recent studies in two major areas of interest. First, we explore the interactions and potential for synergies between lung cancer screening programs and smoking cessation by summarizing reported changes in smoking behavior observed in major screening trials in the US and Europe, as well as attempts to use smoking cessation interventions to augment the benefits from lung cancer screening programs. Second, we review the interaction between smoking habits and pre-/post-operative pulmonary resection outcomes, including changes in smoking behavior post-diagnosis and post-treatment. Information from these areas should allow us to maximize benefits from smoking cessation interventions through the entire lung cancer screening process, from the screen itself through potential curative resection after diagnosis.
\end{abstract}

Keywords Smoking cessation - Lung cancer - CT screening · Lung cancer screening · Resection · Screening trial · Postoperative complications · Quit smoking - NLST . Tobacco policy

\footnotetext{
V. Munshi $(\bowtie) \cdot$ P. McMahon

Institute for Technology Assessment, Massachusetts General

Hospital, 101 Merrimac Street, 10th Floor, Boston,

MA 02114, USA

e-mail: vidit@mgh-ita.org

P. McMahon

Department of Radiology, Harvard Medical School,

Boston, MA, USA
}

\section{Introduction}

In 2011, the National Lung Screening Trial reported that screening heavy smokers annually with three low-dose CTs reduced lung cancer mortality by $20 \%$ compared to screening with three chest radiographs $[1 \bullet \bullet$. CT screening has become a prominent focus in combating lung cancer (with USPSTF draft recommendations released in July $2013[2,3 \bullet]$ ) because screening increases the likelihood of early detection and successful treatment of early stage lung cancers. Prognosis for lung cancer deteriorates rapidly over time, with estimates of 10 -year survival rates for stage I screen-detected lung cancer at over $80 \%$ [4], while 5-year survival estimates for advanced (stage IV) lung cancer are around $10-15 \%$ [5]. These factors contribute to making lung cancer the leading cause of cancer death in the US.

Cigarette smoking causes around $90 \%$ of lung cancers [6]. Despite recent declines in smoking, $19 \%$ of adult Americans were current smokers in 2011 [7], making smoking cessation interventions another important strategy for decreasing lung cancer mortality. Though the reduction in smoking attributed to tobacco control has prevented an estimated 800,000 lung cancer deaths in the US between the period 1975 and 2000 [8•], a large portion of the population remains at risk. Early detection of lung cancer and smoking cessation interventions can decrease lung cancer mortality, but information on the effectiveness and interaction between smoking cessation and lung cancer screening is sparse and inconsistent. This review aims to synthesize recent studies in two major areas of interest. First, we will explore the interactions and potential for synergies between lung cancer screening programs and smoking cessation. We summarize reported changes in smoking behavior observed in major screening trials in the US and Europe, as well as attempts to use smoking 
cessation interventions to augment the benefits from lung cancer screening programs. Second, we will review the interaction between smoking habits and pre-/post-operative pulmonary resection outcomes, including changes in smoking behavior post-diagnosis and post-treatment. Information from these areas of interest should allow us to maximize benefits from smoking cessation interventions through the entire lung cancer screening process, from the screen itself through potential curative resection after diagnosis.

\section{Impact of Screening Trials on Smoking Habits}

The outcomes of a lung cancer screen exam may have a significant impact on a participant's motivations and actions. A positive lung cancer screen can provide participants with a phenomenon known as "a teachable moment $[9,10 \bullet 0, "$ defined as a health event that motivates an individual to adopt risk-reducing health behaviors. The proportion of trial participants with positive CT screening exams depended on the trial design, but averaged $20 \%$, and most (over $90 \%$ ) of these positive screens were falsepositive, ultimately benign findings $[1 \bullet \bullet, 11]$. Thus, for many screened individuals, the scare of a positive test, fear of a potential lung cancer diagnosis, and education from a physician about lung cancer and the dangers of smoking could provide motivation to give up or reduce their smoking habits. On the other hand, a negative screen result may create the opposite effect in which a participant gets a false sense of security from a negative screen result and either continues to smoke or resumes smoking after having previously quit without worry about future consequences. A number of recently completed lung cancer screening trials quantified smoking outcomes in the context of trial results. Later, we will explain the reasons that the analyses below have provided varied, inconsistent results across trials in both the US and Europe.

Eight major randomized trials or cohort studies of lung cancer screening in the past decade, six in the US and two in Europe, have so far reported followed-up smoking outcomes. Key descriptions and results for each of these are given in Table 1. The Early Lung Cancer Action Program (ELCAP) was a study $(n=2,078)$ at New York Presbyterian Hospital that looked at participants that were at least 60 years old with a minimum of 10 pack-years of smoking. In 2001, Ostroff et al. [12] reported that $23.1 \%$ of participants reported they had quit smoking (defined in this report as 30-day abstinence), while $26.1 \%$ had decreased smoking and $2.9 \%$ increased smoking. In the same ELCAP participants, Anderson et al. [13] reported that at 6 years of follow-up, $14 \%$ had quit smoking (defined as 30-day abstinence) and that $4.4 \%$ of former smokers at enrollment had relapsed. A study of 313 current and former smokers referred to as the lung screening study (LSS, a feasibility study for the NLST) assessed current and former smokers' motivations and interest in smoking cessation. In 2007, Taylor et al. [9] reported quit rates (defined as point abstinence) in the LSS of $6.6 \%$ for current smokers and $4.1 \%$ for former smokers at 1-month follow-up. Quit rates in the NLST portion of the study were $7.2 \%$ for current smokers and $4.7 \%$ for formers smokers at follow-up, while the relapse rate was $4 \%$. The Mayo CT study enrolled participants who were at least 50 years old with less than 10 years since quit and greater than 20 pack-years of smoking history. Cox et al. [14] reported a $14 \%$ quit rate (7-day abstinence) at 1-year follow-up. A later study by Townsend et al. [15] with longer follow-up reported 22 and $23 \%$ quit rates (7-day abstinence) at 2 and 3 years, respectively. Relapse rates were as high as $31 \%$ for recent quitters during the study and $3 \%$ for former smokers after 3 years of follow-up. The Pittsburgh Lung Screening Study (PLuSS) enrolled participants 50-70 years of age with a minimum of 0.5 packs/day for 25 years and a maximum 10 years since quit. Styn et al. [16] reported a $16 \%$ quit rate (30-day abstinence) and a $12 \%$ relapse rate for recent quitters at a 1-year follow-up interview.

Two major trials in Europe examined smoking abstinence in the presence of CT lung cancer screening. The ongoing Dutch-Belgian NELSON trial enrolled 50-75year-old participants with a minimum of 15 cigarettes/day for at least 25 years or a minimum of 10 cigarettes/day for at least 30 years with a maximum of 10 years since quit. Van der Aalst et al. [17, 18] reported an insignificant $13 \%$ quit rate (7-day abstinence) in the CT group and $15 \%$ in the control group at 2-year follow-up. In further follow-up within the CT group, there was an insignificant $8.9 \%$ quit rate in the CT group with negative results compared to $11 \%$ in the group with indeterminate results. The Danish Lung Cancer Screening Trial (DLCST) enrolled participants between the ages of 50-70 with greater than 20 packyears and maximum years since quit of 10 . Ashraf et al. [19] reported quit rates of $11.9 \%$ in the CT group and $11.8 \%$ in the control group (4-weeks abstinence), with relapse rates of 10 and $10.5 \%$, respectively.

While the previous analyses were done in trials comparing CT to chest radiograph or to usual care, two other trials comparing chest radiographs to usual care also reported changes in smoking status. Though the difference in smoking outcomes between CT and radiograph screening is unclear, we might speculate there will be higher quit rates in a CT screening arm with more detected nodules and false positives. The PLCO compared chest radiograph screening to usual care in a group with no eligibility requirement (including non-smokers). Barry et al. [20•] followed up participants 4-14 years after enrollment and 
Table 1 Overview of smoking status changes during major lung cancer screening trials and studies in the US and Europe

\begin{tabular}{|c|c|c|c|c|}
\hline Screening trial & $N$ & Eligibility criteria & Smoking endpoints reported & $\begin{array}{l}\text { Source(s) for } \\
\text { smoking } \\
\text { endpoints }\end{array}$ \\
\hline ELCAP & $\begin{array}{l}134(40.3 \% \\
\text { male })\end{array}$ & Age $>60$, pack-years $(\mathrm{PY})>10$ & $\begin{array}{l}\text { Quit rate: } 23.1 \% \\
\text { Relapse rate: } 3 \% \text { "increased" } \\
\text { smoking }\end{array}$ & Ostroff et al. [12] \\
\hline ELCAP & $\begin{array}{l}2,078(44.8 \% \\
\text { male })\end{array}$ & Age $>60$, PY $>10$ & $\begin{array}{l}\text { Quit rate: } 14 \% \text { (up to } 6 \text { years) } \\
\text { Relapse rate: } 4.4 \% \text { (former } \\
\text { smokers) } \\
34-42 \% \text { for recent quitters }\end{array}$ & $\begin{array}{l}\text { Anderson et al. } \\
\text { [13] }\end{array}$ \\
\hline Mayo CT (1 year F/U) & $\begin{array}{l}1,475(49.7 \% \\
\text { male })\end{array}$ & $\begin{array}{l}\text { Age }>50, \text { PY }>20, \text { years since } \\
\text { quit }(Y S Q)<10\end{array}$ & $\begin{array}{l}\text { Quit rate: } 14 \% \text { (1 year) } \\
\text { Relapse rate: N/A }\end{array}$ & Cox et al. [14] \\
\hline Mayo CT (3 years F/U) & $\begin{array}{l}1,520(51.7 \% \\
\text { male })\end{array}$ & Age $>50$, PY $>20$, YSQ $<10$ & $\begin{array}{l}\text { Quit rate: } 22 \% \text { (2 years); } 24 \% \\
\text { (3 years) } \\
\text { Relapse rate: } 2.3 \%, 2.7 \%, \\
3.0 \% \text { (at } 1,2,3 \text { years) } \\
26-32 \% \text { for recent quitters }\end{array}$ & $\begin{array}{l}\text { Townsend et al. } \\
\text { [15] }\end{array}$ \\
\hline NLST/LSS feasibility study & $\begin{array}{l}\text { LSS: } 144 \\
\quad(51.8 \%) \\
\text { NLST: } 169 \\
(57 \%)\end{array}$ & $\begin{array}{l}\text { NLST: age } 55-75, \mathrm{PY}>30 \\
\text { YSQ }<10\end{array}$ & $\begin{array}{l}\text { Quit rate: } 6.3 \% \text { (NLST); } 4.8 \% \\
\text { (LSS) } \\
\text { Relapse: } 4.4 \% \text { (NLST); } 3.3 \% \\
\text { (LSS)_former smokers }\end{array}$ & Taylor et al. [9] \\
\hline DLCST & $\begin{array}{l}4,104(55 \% \\
\text { male })\end{array}$ & Age: $50-70$, PY $>20$ YSQ $<10$ & $\begin{array}{l}\text { Quit rate (1 year F/U): } 11 \%(\mathrm{CT} \\
\text { group), } 10 \% \text { (control) } \\
\text { Relapse rate: } 9.3 \% \text { (CT group), } \\
9.3 \% \text { (control) }\end{array}$ & Ashraf et al. [46] \\
\hline PLuSS & $\begin{array}{l}2,094(49.3 \% \\
\text { male })\end{array}$ & $\begin{array}{l}\text { Age: } 50-79, \text { YSQ }<10, \text { min } 0.5 \\
\text { packs per day for } 25 \text { years }\end{array}$ & $\begin{array}{l}\text { Quit rate: } 16 \%(1 \text { year }) \\
\text { Relapse rate: } 12 \% \text { for recent } \\
\text { quitters }\end{array}$ & Styn et al. [16] \\
\hline $\begin{array}{l}\text { NELSON (analysis of smokers } \\
\text { at baseline questionnaire) }\end{array}$ & 1,284 & Age: $50-75$ & $\begin{array}{l}\text { Quit rate: } 13 \% \text { (CT group), } \\
15 \% \text { (control)—2 years F/U }\end{array}$ & $\begin{array}{l}\text { van der Aalst } \\
\text { et al. [18] }\end{array}$ \\
\hline Mayo lung project (CXR) & 9,211 & Smokers age $>45$ & $\begin{array}{c}\text { Quit rate: } 7.5 \% \text { (intervention), } \\
7.5 \% \text { (control)—1 year } \mathrm{F} / \mathrm{U}\end{array}$ & Shi et al. [21] \\
\hline PLCO screening trial (CXR) & $\begin{array}{l}\text { 6,807 (current) } \\
31,694 \text { (former) }\end{array}$ & Age: $55-74$ & $\begin{array}{l}\text { Quit rate: } 34.8 \% \text { (current at } \\
\text { baseline) } \\
\text { Relapse rate: } 3.3 \% \text { (former at } \\
\text { baseline) }\end{array}$ & Barry et al. $\left[20^{\bullet}\right]$ \\
\hline
\end{tabular}

Except where noted, the screen modality was CT

ELCAP Early Lung Cancer Action Program, NLST National Lung Screening Trial, LSS lung screening study, DLCST Danish Lung Cancer Screening Trial, PLuSS Pittsburgh Lung Screening Study, PLCO Prostate, Lung, Colorectal, and Ovarian Cancer Screening Trial

reported that $65.2 \%$ of current smokers had continued smoking, while $3.3 \%$ of former smokers had relapsed. Shi et al. [21] reported no significant difference in smoking status between the chest radiograph and control groups (quit rate of $7.5 \%$ in both groups at 1-year follow-up) in the Mayo Lung Project, which compared chest radiographs to usual care in older smokers.

Numerous differences across these analyses make it very difficult to compare them directly. In many cases, comparisons of quit rates by arm are insignificant, but the power to detect changes in behavior is limited because of small sample sizes. Furthermore, criteria such as the definition of "quitting" are arbitrary and vary widely across trials. For example, the Mayo CT defined quitting as a 7-day abstinence from smoking, while ELCAP used 30 days as a guideline. The NELSON trial also used 7 days, but additionally required fewer than five cigarettes smoked since 2 weeks after the quit date. In the Healthy People 2020 Objectives, the definition of "recent smoking cessation" is a former smoker who has quit in the past year and has not smoked for more than 6 months prior to interview [22]. Also, as mentioned in the trial participation criteria, age ranges, minimum pack-years, and minimum cigarettes per day varied within the trials. Finally, these studies looked at volunteer populations, many of which enrolled in trials with no usual care arm, so observed 
smoking cessation rates may not be completely applicable to the general population in which individuals meeting the screening eligibility criteria are referred for screening by their primary care physicians.

\section{Smoking Cessation Combined with Lung Cancer Screening}

While some questions remain on the effectiveness of a lung cancer screening program in changing participants' smoking habits, there is very little information on the effectiveness of smoking cessation therapies combined with screening. The NELSON trial analyzed the effectiveness of a smoking cessation intervention integrated with the screening trial. Van der Aalst et al. [23••] reported that a group $(n=642)$ given a tailored self-help cessation intervention had lower, though insignificant, rates of prolonged (defined as smoking less than five cigarettes per day for 2 weeks after quit date) abstinence $(12.5 \%)$ compared to a control group $(n=642)$ that received standard brochures $(15.6 \%)$. Unfortunately, only $23 \%$ of the participants in the tailored information group returned their questionnaire and received tailored advice, making results difficult to interpret. Clark et al. [24] found that smokers undergoing $\mathrm{CT}$ for lung cancer screening in the Mayo CT were more likely to make a quit attempt after having received Internet-based resources (68\%) compared to those who received standard self-help materials (48\%, $p=0.011$ ). However, the study found no significant difference in 7-day abstinence between the two groups. A pilot test by Ferketich et al. [25•] that included a tobacco dependence treatment along with lung cancer screening reported a quit rate (defined as 7-day abstinence) of $33.3 \%$ in the arm that provided the intervention prior to screening compared to $22.2 \%$ after screening, suggesting that delivery of cessation interventions may be more effective prior to lung cancer screening. In addition to trial result analyses, McMahon et al. [26 $6^{\circ}$ used a microsimulation model to estimate the cost-effectiveness of lung cancer screening in combination with smoking cessation therapies. They predicted costs well over $\$ 100,000 / \mathrm{QALY}$ for screening/cessation combination programs compared to no intervention. However, they concluded that the ability of CT lung cancer screening programs to influence participants' smoking cessation rates would play a significant role in determining the cost-effectiveness of the screening program overall.

\section{Impact on Surgery}

Because of trial participation eligibility requirements, lung cancer screening trial participants are much heavier smokers than smokers in the general population and at a higher risk of lung cancer. Though former smokers were eligible, many participants in the trials described above were current heavy smokers (approximately $48 \%$ in the NLST $[1 \bullet \cdot)$. As a result, discovery of nodules and potential lung cancers through trial screening and follow-up protocols leads to an increased number of lung cancer surgeries. Recent studies described below suggest that current smokers have a higher likelihood of postoperative complications (including mortality [27]) compared to former smokers, often resulting in decreased quality of life [28, 29]. More broadly, ever-smokers have a higher likelihood of postoperative complications compared to neversmokers.

In 2013, Seok et al. [30••] looked at 232 cancer patients between 2005 and 2009 and found that smoking was not a risk factor for postoperative complications, concluding that delaying surgery in order to get a significant duration of smoking cessation was unnecessary. On the other hand, a 2010 review by Thomsen et al. [31 ${ }^{\bullet}$ ] analyzed eight trials, including seven that offered or recommended nicotine replacement therapy (NRT) as an intervention, and concluded that preoperative smoking interventions including NRT may reduce postoperative morbidity. Furthermore, a 2011 study by Balducyk et al. analyzing questionnaires given to 20 patients concluded that smoking at the time of surgery was associated with decreased postoperative quality of life and that smoking cessation at any point prior to lung cancer surgery would be beneficial. Mason et al. [32] looked at outcomes from a large group of patients $(n=7,990)$ who had undergone resection between 1999 and 2007 to assess risk of hospital death and complications relative to time of smoking cessation. They found that mortality in the hospital was $1.5 \%$ for patients who had smoked compared to $0.39 \%$ for non-smokers $(p=0.03$, current smokers). Furthermore, complications occurred in $6.2 \%$ of patients who had smoked compared to $2.5 \%$ of those who hadn't ( $p=0.03$, current smokers). Thus, there is a benefit to quitting, but patients do not always benefit from this information. Cooley et al. [33] collected smoking status and history from 94 patients recovering from lung cancer surgery as part of a multi-hospital (US) study between 2002 and 2006 and reported that only $46 \%$ of patients had received cessation assistance prior to surgery.

Other studies have focused on the timing of smoking cessation interventions relative to surgery. Zaman et al. [34•] analyzed seven studies [35] looking at the interval of smoking cessation prior to surgery and concluded that an "optimal interval of cessation has not been identified." Barrera et al., Groth et al., Sawabata et al., and Shimizu et al. [36-39] each found no significant difference in postoperative pulmonary complications due to differences in timing of smoking cessation. Nakagawa et al. [40] found that smoking cessation resulting in at least 4 weeks of 
smoking abstinence prior to surgery showed a reduction in development of complications. Another study by Slatore et al. [41] looked at the cost-effectiveness of a smoking cessation and found it to be cost-effective at both 1 and 5 years after surgery.

While previous studies also discuss the benefit of preoperative smoking cessation efforts and the drawbacks of smoking prior to curative resection, a 2013 review of preoperative smoking cessation effects on lung cancer surgery outcomes by Schmidt-Hansen et al. [42*0] reported that "The included studies were marked by methodological limitations. On the basis of the reported bodies of evidence, it is not possible to make any firm conclusions about the effect of preoperative smoking cessation or of preoperative pulmonary rehabilitation on operative outcomes in patients undergoing surgery for lung cancer."

\section{Conclusions}

Cooley et al. [43] reported that after diagnosis of cancer, around $50 \%$ of patients were interested in smoking cessation programs, further highlighting the need to develop interventions. While studies vary regarding the degree to which lung cancer screening programs affect smoking cessation, most agree that lung cancer screening programs should promote smoking cessation and that smoking cessation-related interventions are an important factor to consider in any lung cancer screening program.

However, it is difficult to make conclusions based on recent lung cancer screening trials in the US and Europe because of inconsistencies in trial characteristics, lack of smoking history follow-up, small sample sizes, and other limitations. Studies specifically focused on smoking status in the context of smoking cessation interventions as part of lung cancer screening in the community are needed to gain more information on the potential for synergy. Furthermore, these studies need to be consistent in terms of follow-up time, cohort characteristics, definitions of smoking abstinence, and other important factors. Since several organizations such as the American Cancer Society, American College of Chest Physicians, American Society of Clinical Oncology, American Thoracic Society, and National Comprehensive Cancer Network Guidelines have followed up the results of the NLST with recommendations of lung cancer screening closely modeling the NLST, a registry that collects standardized information (screen participation, screen results, smoking behavior at defined intervals, etc.) would be an important tool for researchers to conduct meaningful analyses in this field. Additionally, more information on smoking history changes in the NLST itself should be published in the near future, giving a glimpse into what effects we may expect in this volunteer, heavy-smoking population. Though smoking cessation interventions were not part of the trial, these analyses should provide information on smoking behavior changes in response to positive and negative screens.

Similar to the issues faced in determining smoking changes in lung cancer screening programs, existing studies focusing on the relationship between smoking and postoperative outcomes were inconsistent and difficult to compare. As a result, conclusions are varied. Though most authors agree that smoking cessation interventions prior to surgery are important and will lead to better outcomes [44, 45], more consistent trials and significant results are required to quantify these effects and make any definitive determinations. Overall, further studies and comparative effectiveness analyses on patient outcomes data that include smoking status are required in order to determine the magnitude of the role that smoking cessation interventions and therapies can play in lung cancer screening programs. Furthermore, these studies should extend to lung cancer surgeries and the differences in outcomes between participants who quit or continue smoking during the course of a trial.

Cigarette smoking is a major contributor to poor health, and several components of the Patient Protection and Affordable Care Act (ACA) target tobacco use. Under the ACA, about 25 million more Americans are expected to gain health insurance, which will include no cost-sharing for tobacco cessation and lung cancer screening (if recommended by the US Preventive Services Task Force with an A or B recommendation, \$2713 of ACA). Together, evidence from available studies, improved data collection and outcomes reporting, and changes in access to effective interventions for tobacco cessation will allow physicians to better guide patients through the screening to treatment process and improve patient outcomes along the way.

\section{Compliance with Ethics Guidelines}

Conflict of Interest Pamela McMahon has received grant support from the National Cancer Institute (no. U01CA152956). Vidit Munshi declares that he has no conflict of interest.

Human and Animal Rights and Informed Consent This article does not contain any studies with human or animal subjects performed by any of the authors.

\section{References}

Papers of particular interest, published recently, have been highlighted as:

- Of importance

•- Of major importance

1. • Aberle DR, Adams AM, Berg CD, et al. Reduced lung-cancer mortality with low-dose computed tomographic screening. 
N Engl J Med. 2011;365(5):395-409. This paper details the recently completed NLST, which reported $20 \%$ mortality reduction using CT for screening compared to CXR. Numerous guideline recommendations are being made based on NLST trial results.

2. US Preventitive Services Task Force. Lung cancer screening, topic page. http://www.uspreventiveservicestaskforce.org/uspstf/ uspslung.htm. Accessed August 2013.

3. - Humphrey LL, Deffebach M, Pappas M, et al. Screening for lung cancer with low-dose computed tomography: a systematic review to update the US Preventive Services Task Force Recommendation. Ann Intern Med. 2013. This review is an update of all recent and important findings in lung cancer screening to update the US Preventitive Services Task Force prior to lung cancer screening recommendations.

4. Henschke CI, Yankelevitz DF, Libby DM, et al. Survival of patients with stage I lung cancer detected on CT screening. N Engl J Med. 2006;355(17):1763-71.

5. American Lung Association. Trends in Lung Cancer Morbidity and Mortality. http://www.lung.org/finding-cures/our-research/ trend-reports/lc-trend-report.pdf. Accessed July 2013.

6. Centers for Disease Control and Prevention. Lung cancer: risk factors. Available at http://www.cdc.gov/cancer/lung/basic_info/ risk_factors.htm. Accessed July 2013.

7. Centers for Disease Control and Prevention (CDC). MMWR Morb Mortal Wkly Rep. Current cigarette smoking among adults—United States, 2011. http://www.cdc.gov/mmwr/preview/ mmwrhtml/mm6144a2.htm. Accessed July 2013.

8. - Moolgavkar SH, Holford TR, Levy DT, et al. Impact of reduced tobacco smoking on lung cancer mortality in the United States during 1975-2000. J Natl Cancer Inst. 2012;104(7):541-8. This paper reports comparative modeling results from six lung cancer models to estimate the impact of tobacco control policies on smoking behvaoir and lung cancer deaths in the period 1975-2000.

9. Taylor KL, Cox LS, Zincke N, et al. Lung cancer screening as a teachable moment for smoking cessation. Lung Cancer. 2007; 56(1):125-34.

10. $\bullet$ Poghosyan H, Kennedy Sheldon L, Cooley ME. The impact of computed tomography screening for lung cancer on smoking behaviors: a teachable moment? Cancer Nurs. 2012;35(6): 446-75. This paper reviews literature on the impact of CT lung cancer screening on the smoking behavior of current smokers.

11. Bach PB, Mirkin JN, Oliver TK, et al. Benefits and harms of CT screening for lung cancer: a systematic review. JAMA. 2012; 307(22):2418-29.

12. Ostroff JS, Buckshee N, Mancuso CA, et al. Smoking cessation following CT screening for early detection of lung cancer. Prev Med. 2001;33:613-21.

13. Anderson CM, Yip R, Henschke CI, et al. Smoking cessation and relapse during a lung cancer screening program. Cancer Epidemiol Biomarkers Prev. 2009;18(12):3476-83.

14. Cox LS, Clark MM, Jett JR, et al. Change in smoking status after spiral chest computed tomography scan screening. Cancer. 2003;98(11):2495-501.

15. Townsend CO, Clark MM, Jett JR, et al. Relation between smoking cessation and receiving results from three annual spiral chest computed tomography scans for lung carcinoma screening. Cancer. 2005;103(10):2154-62.

16. Styn MA, Land SR, Perkins KA, et al. Smoking behavior 1 year after computed tomography screening for lung cancer: effect of physician referral for abnormal CT findings. Cancer Epidemiol Biomarkers Prev. 2009;18(12):3484-9.

17. van der Aalst CM, van Klaveren RJ, van den Bergh KA, et al. The impact of a lung cancer CT screening result on smoking abstinence. Eur Respir J. 2011;37(6):1466-73.
18. van der Aalst CM, van den Bergh KA, Willemsen MC, et al. Lung cancer screening and smoking abstinence: 2 year follow-up data from the Dutch-Belgian randomised controlled lung cancer screening trial. Thorax. 2010;65(7):600-5.

19. Ashraf $\mathrm{H}$, Tonnesen $\mathrm{P}$, Holst Pedersen $\mathrm{J}$, et al. Effect of CT screening on smoking habits at 1-year follow-up in the Danish Lung Cancer Screening Trial (DLCST). Thorax. 2009;64(5): 388-92.

20. - Barry SA, Tammemagi MC, Penek S, et al. Predictors of adverse smoking outcomes in the Prostate, Lung, Colorectal and Ovarian Cancer Screening Trial. J Natl Cancer Inst. 2012;104(21):1647-59. This paper uses data from the PLCO trial to analyze smoking variables that affect long-term smoking outcomes and identify individuals at risk of relapse using a risk prediction model.

21. Shi L, Iguchi MY. "Risk homeostasis" or "teachable moment"? The interaction between smoking behavior and lung cancer screening in the Mayo Lung Project. Tob Induc Dis. 2011;9(1):2.

22. Centers for Disease Control and Prevention. Quitting smoking among adults-United States, 2001-2010. MMWR Morb Mortal Wkly Rep. http://www.cdc.gov/mmwr/preview/mmwrhtml/mm60 44a2.htm. Accessed July 2013.

23. • van der Aalst CM, de Koning HJ, van den Bergh KA, et al. The effectiveness of a computer-tailored smoking cessation intervention for participants in lung cancer screening: a randomised controlled trial. Lung Cancer. 2012;76(2):204-10. The NELSON trial was the only one out of the major lung screening trials to include a smoking cessation intervention as part of the trial. This paper analyzes the effectiveness of the intervention.

24. Clark MM, Cox LS, Jett JR, et al. Effectiveness of smoking cessation self-help materials in a lung cancer screening population. Lung Cancer. 2004;44(1):13-21.

25. - Ferketich AK, Otterson GA, King M, et al. A pilot test of a combined tobacco dependence treatment and lung cancer screening program. Lung Cancer. 2012;76(2):211-5. This pilot study assessed the feasibility of incorporating a smoking cessation program in conjunction with lung cancer screening.

26. - McMahon PM, Kong CY, Bouzan C, et al. Cost-effectiveness of computed tomography screening for lung cancer in the United States. J Thorac Oncol. 2011;6(11):1841-8. This paper uses a microsimulation model to estimate cost-effectiveness of CT lung cancer screening and predict cost-effectiveness of hypothetical programs combining smoking cessation therapies with lung cancer screening.

27. Erhunmwunsee L, Onaitis MW. Smoking cessation and the success of lung cancer surgery. Current Oncol Rep. 2009;11(4): 269-74.

28. Balduyck B, Sardari Nia P, Cogen A, et al. The effect of smoking cessation on quality of life after lung cancer surgery. Eur $\mathrm{J}$ Cardiothorac Surg. 2011;40(6):1432-7 discussion 1437-8.

29. Chen J, Qi Y, Wampfler JA, et al. Effect of cigarette smoking on quality of life in small cell lung cancer patients. Eur J Cancer. 2012;48(11):1593-601.

30. • Seok Y, Hong N, Lee E. Impact of smoking history on postoperative pulmonary complications: a review of recent lung cancer patients. Ann Thorac Cardiovasc Surg. 2013. This is a recent analysis of lung cancer patients between 2005 and 2009 to assess the impact of smoking behavior on postoperative pulmonary complications.

31. - Thomsen T, Villebro N, Moller AM. Interventions for preoperative smoking cessation. Cochrane Database Syst Rev. 2010(7):CD002294. This paper reviews literature on trials assessing the effect of preoperative smoking cessation interventions on smoking cessation at and after the time of surgery as well as incidence of postoperative complications. 
32. Mason DP, Subramanian S, Nowicki ER, et al. Impact of smoking cessation before resection of lung cancer: a Society of Thoracic Surgeons General Thoracic Surgery Database study. Ann Thorac Surg. 2009;88(2):362-70 discussion 370-1.

33. Cooley ME, Sarna L, Kotlerman J, et al. Smoking cessation is challenging even for patients recovering from lung cancer surgery with curative intent. Lung Cancer. 2009;66(2):218-25.

34. - Zaman M, Bilal H, Mahmood S, Tang A. Does getting smokers to stop smoking before lung resections reduce their risk? Interact Cardiovasc Thorac Surg. 2012;14(3):320-3. This paper reviews extensive literature on the question of whether major pulmonary morbidity after lung resection is associated with timing of smoking cessation.

35. Vaporciyan AA, Merriman KW, Ece F, et al. Incidence of major pulmonary morbidity after pneumonectomy: association with timing of smoking cessation. Ann Thorac Surg. 2002;73(2):420-5 discussion 425-426.

36. Barrera R, Shi W, Amar D, et al. Smoking and timing of cessation: impact on pulmonary complications after thoracotomy. Chest. 2005;127(6):1977-83.

37. Groth SS, Whitson BA, Kuskowski MA, et al. Impact of preoperative smoking status on postoperative complication rates and pulmonary function test results 1-year following pulmonary resection for non-small cell lung cancer. Lung Cancer. 2009;64(3):352-7.

38. Sawabata N, Miyoshi S, Matsumura A, et al. Prognosis of smokers following resection of pathological stage I non-smallcell lung carcinoma. Gen Thorac Cardiovasc Surg. 2007;55(10): $420-4$.

39. Shimizu K, Nakata M, Hirami Y, et al. Recent results regarding the clinical impact of smoking history on postoperative complications in lung cancer patients. Interact Cardiovasc Thorac Surg. 2008;7(6):1001-6.

40. Nakagawa M, Tanaka H, Tsukuma H, Kishi Y. Relationship between the duration of the preoperative smoke-free period and the incidence of postoperative pulmonary complications after pulmonary surgery. Chest. 2001;120(3):705-10.

41. Slatore CG, Au DH, Hollingworth W. Cost-effectiveness of a smoking cessation program implemented at the time of surgery for lung cancer. J Thorac Oncol. 2009;4(4):499-504.

42. • Schmidt-Hansen M, Page R, Hasler E. The effect of preoperative smoking cessation or preoperative pulmonary rehabilitation on outcomes after lung cancer surgery: a systematic review. Clin Lung Cancer. 2013;14(2):96-102. This paper is a recent systematic review of literature to determine effectiveness of preoperative smoking cessation and pulmonary rehabilitation on periand postoperative outcomes in patients undergoing lung cancer resection.

43. Cooley ME, Emmons KM, Haddad R, et al. Patient-reported receipt of and interest in smoking-cessation interventions after a diagnosis of cancer. Cancer. 2011;117(13):2961-9.

44. Mazzone P. Preoperative evaluation of the lung resection candidate. Cleve Clin J Med. 2012;79:eS17-22.

45. Parsons A, Daley A, Begh R, Aveyard P. Influence of smoking cessation after diagnosis of early stage lung cancer on prognosis: systematic review of observational studies with meta-analysis. BMJ. 2010;340:b5569.

46. Ashraf H, Tonnesen P, Pedersen JH, et al. Smoking habits were unaffected by CT screening at 1-year follow-up in the Danish Lung Cancer Screening Trial (DLCST). Thorax. 2008;64(5): 388-92. 